\title{
QUALITY-OF-LIFE IN MODERN SOCIETY Measured with Happy Life Years ${ }^{1}$
}

\section{Ruut Veenhoven}

\author{
Chapter 2 inYew-Kwang Ng \& Lok Sang Ho (Eds.) 'Happiness and Public Policy, \\ Theory, Case studies and Implications' Palgrave, Macmillan, New York, 2006, ISBN \\ 13: 978-0-230-00497-9, pp.19-44.
}

\section{INTRODUCTION}

\subsection{Contrary views on the quality-of-life in modern society}

The human species has lived for most of its time in simple hunter-gatherer societies. Agrarian societies developed less than 5.000 years ago and it is only in the last 200 years that a 'modern' industrial society has come into being. Today this industrial society is rapidly transforming into a global information society.

Is this societal evolution a change for the better? There has always been much controversy over this question, and currently the dispute seems more intense than ever, possibly for the reason that we are more aware today that society is of our making and because social change is taking place at an ever increasing rate. One of the issues in this ongoing debate is the quality-of-life in modern society ${ }^{2}$. Progress optimists believe that life is getting better, while pessimists argue that life is getting worse.

\subsection{The positive view}

The idea that life is getting better draws on several achievements of modern society. One is the unprecedented rise in the material standard of living; the average citizen lives more comfortably now than kings did a few centuries ago. Another improvement that strikes the eye is that the chance of an untimely death is greatly reduced; ever fewer people die in accidents and epidemics and fewer are murdered. A number of social evils have been abated, such as poverty, inequality, ignorance and oppression. A recent statement of this view can be found in 'Its getting better all the time' by Moore and Simon (2000).

This notion of improvement is typically part of an evolutionary view, in which society is seen as a human tool that is gradually perfected. This idea developed during the period of Enlightenment in the 18th century and lives today. The idea that we can improve society by 'social engineering' is part of this belief and it forms the ideological basis of many major contemporary institutions, such as the welfare state and development aid organizations.

The idea that life is getting better breaks with the traditional religious view of earthly life as a phase of penance awaiting paradise in the afterlife. It is deemed possible to reduce suffering by creating a better world and societal development is seen to head in that way, be it with some ups and downs. 


\subsection{The negative view}

The view that life is getting worse is typically fuelled by concern about contemporary social problems. One kind of problems is deviant behavior, such as criminality, drug use and school refusal. Another group of problems seen to reduce the quality of life is social conflicts, such as labor disputes, ethnic troubles and political terrorism. The decline of the influence of the church, the family and the local community are also seen to impoverish the quality of life of modern people, as are the rising divorce rates. A recent statement of this view can be found in: 'The progress paradox: How life gets better while people feel worse’ by Easterbrook (2003).

This notion of decay is often part of the idea of society drifting away from human nature, because society has changed a lot, while human nature has not. In this view society is not a piece of equipment, but rather an uncontrollable force that presses humans into a way of life that does not really fit them. The notion of decay fits also with the supposition that there is great wisdom and morality in tradition, which modernization destroys.

The idea that life is getting worse fits a long tradition of social criticism and apocalyptic prophecies. In this view, paradise is lost and is unlikely to be restored.

\subsection{Dominance of the negative view}

The negative view prevails in most discussions and, in particular, in social scientific discourse. This appears both in classic theory and in social reporting, and the negative view has also gained the upper hand in public opinion.

\subsubsection{Themes in classic social theory}

Many renowned social theorists were typically not very positive about the quality-of-life in modern society. For instance, Karl Marx (1871) prophesied that the blind forces of capitalism would result in a process of 'Verelendung' (miserysation), the working class getting ever poorer and becoming even larger. In this line Braverman (1974) argued that mechanization and specialization 'degraded' work in the $20^{\text {th }}$ century.

Sociologist Emile Durkheim (1897) was also not very positive and observed growing moral disorientation, which he called 'anomie'. In his view, the modernization process disrupts the communal basis of morality, amongst other things because social control is reduced, and he provided evidence that this development had boosted suicide rates. Many later sociologists, who also see increasing loneliness and feelings of meaninglessness in modern society, echo this view. Appealing books written in this tradition include Riesman's (1950) "Lonely crowd', Ritzer’s (1993) “The McDonaldization of society” and Putnam's (2000) 'Bowling alone”. Sociologists have become more negative about modern society over the last decade, an analysis of the Sociological Abstracts showed a doubling in the use of gloomy words between 1970 and 2000 (Elchardus 2004: 507).

In psychology, Freud (1930) provides an outspoken example of the theory that life is getting worse. In his 1923 book "Unbehagen in der Kultur" (Society and its Discontents) Freud asserts that any social organization requires the repression of instinctual urges, and that the development of modern society necessitates ever more repression of natural impulses. Hence he believed that societal civilization is antithetical 
to human happiness and that we are typically less happy than our primitive forefathers. Likewise some evolutionary psychologists believe that natural selection cannot keep pace with societal development (e.g. Nesse 2004:1343).

\subsubsection{Focus in social reporting}

Social statistics do not suggest that life is getting better in modern society, since they deal with misery in the first place. There are statistics for accidents rates, suicide rates, depression rates, drug abuse, victimization and poverty, but few for enjoyment of life. Moreover social reports tend to emphasize negative trends on these matters. This is at least the case in current western society; in the former communist countries social statistics were typically used to emphasize positive developments in an attempt to conceal a deteriorating quality-of-life.

\subsubsection{Majority in public opinion}

Survey studies in modern nations show wide support for the idea that life was better in the 'good old days'. In the USA the majority agrees with the statement "In spite of what some people say, the lot of the average man is getting worse, not better". Support for this idea is growing, the percent affirmative answers rose from about 55\% in the 1970 s to $70 \%$ in the early 1990s. Curiously, this idea is not reflected in self-reports of an individual's own life, since most people feel that the quality of their personal life has improved (Hagerty 2003).

\section{$1.5 \quad$ Relevance of the issue}

This discussion is not just some academic matter to be argued over in ivory towers; it has profound policy implications.

If modernization makes society less livable, we should try to stop the process, or at least to slow it down. Conservatives have a strong point in this case and can convincingly argue for restorative policies. However, if modernization tends to improve the quality-of-life, we need to accept this development, which would fit the liberal political agenda. In the latter case there is also ground to further modernization, which would support various reformist tendencies in advanced nations and justifies missionary activities such as 'development aid' for 'under developed' nations.

Another implication might be in communication. If majority opinion is wrong and life is getting better instead of worse, the public is apparently misinformed.

\section{MEASUREMENT OF QUALITY-OF-LIFE IN NATIONS}

How can we assess whether life gets better or worse? This first requires a clear definition of quality-of-life and next a feasible operationalisation of this concept. 


\subsection{Concepts of 'quality of life'}

The term 'quality-of-life' serves as a catchword for different notions of the good life. It is used in fact to denote a bunch of qualities of life, which can be ordered on the basis of the following two distinctions.

A first distinction is between opportunities for a good life and the outcomes of life. This distinction is quite common in the field of public-health research. Pre-conditions for good health, such as adequate nutrition and professional care are seldom mixed up with the concept of health. A second difference is between external and inner qualities. In the first case the quality is in the environment, in the latter it is in the individual. This distinction is also quite common in public health. External pathogens are distinguished from inner afflictions. Combining of these two dichotomies yields a fourfold matrix, presented in Table 2.1.

In the upper half of table 2.1, we see, next to the outer opportunities in one's environment, the inner capacities required to exploit these. The environmental conditions can be denoted by the term livability, the personal capacities with the word life-ability. This difference is not new. In sociology, the distinction between 'social capital' and 'psychological capital' is sometimes used in this context, and in the psychology of stress the difference is labeled negatively in terms of 'burden' and 'bearing power'.

The lower half of table 2.1 is about the quality of life with respect to its outcomes. These outcomes can be judged by their value for one's environment and by their value for oneself. The external worth of a life is denoted by the term utility of life. The inner valuation of a life is called appreciation of life. These matters are of course related. Knowing that one's life is useful will typically add to ones appreciation of life. Yet useful-lives are not always happy lives and not every 'good-for-nothing' is unhappy.

\subsubsection{Livability of the environment}

The left top quadrant denotes the meaning of good living conditions, which I call 'livability'. One could also speak of the 'habitability' of an environment, though that term is also used for the quality of housing in particular. Elsewhere I have explored the concept of livability in more detail (Veenhoven 1996:7-9).

Ecologists see livability in the natural environment and describe it in terms of pollution, global warming and degradation of nature. Currently, they associate livability typically with environmental preservation. City planners see livability in the built environment and associate it with sewer systems, traffic jams and ghettos. Here the good life is seen to be the fruit of human intervention. In public health this all is referred to as a 'sane' environment.

Society is central in the sociological view. Firstly, livability is associated with the quality of society as a whole. Classic concepts of the 'good society' stress material welfare and social equality, sometimes equating the concept more or less with the welfare state. Current communitaristic notions emphasize close networks, strong norms and active voluntary associations. The reverse of this livability concept is 'social fragmentation'. Secondly, livability is seen in one's position in society. For a long time, the emphasis was on the 'under-class' but currently attention is shifting to the 'outer-class'. The corresponding antonyms are 'deprivation' and 'exclusion'. 


\subsubsection{Life-ability of the person}

The right top quadrant denotes inner life-chances. That is: how well we are equipped to cope with the problems of life. I call this 'life-ability', which contrasts elegantly with 'livability'.

The most common depiction of this quality of life is an absence of functional defects. This is 'health' in the limited sense, sometimes referred to as 'negative health'. In this context, doctors focus on unimpaired functioning of the body, while psychologists stress the absence of mental defects. This use of words presupposes a 'normal' level of functioning. A good quality of life is seen to be the body and mind working as designed. This is the common meaning used in curative care.

Next to absence of disease, one can consider excellence of function. This is referred to as 'positive health' and associated with energy and resilience. Psychological concepts of positive mental health also involve autonomy, reality control, creativity and inner synergy of traits and strivings. This broader definition is the favorite of the training professions and is central to the 'positive psychology' movement.

\subsubsection{Utility of life}

The left bottom quadrant represents the notion that a good life must be good for something more than itself. I refer to these external turnouts as the 'utility' of life.

When evaluating the external effects of a life, one can consider its functionality for the environment. In this context, doctors stress how essential a patient's life is to their intimates. At a higher level, quality of life is seen as a contribution to society. Historians see quality in the additions an individual can make to human culture, and rate for example the lives of great inventors higher than those of anonymous peasants. Moralists see quality in the preservation of the moral order, and would deem the life of a saint to be better than that of a sinner. In this vein, the quality of a life is also linked to effects on the ecosystem. Ecologists see more quality in a life lived in a 'sustainable' manner than in the life of a polluter.

\subsubsection{Enjoyment of life}

Finally, the bottom right quadrant represents the inner outcomes of life. That is the quality of life in the eye of the beholder. As we deal with conscious humans, this quality boils down to subjective appreciation of life. This is commonly referred to by terms such as 'subjective wellbeing', 'life-satisfaction' and 'happiness' in a limited sense of the word.

Humans are capable of evaluating their life in different ways. We have, in common with all higher animals, an ability to appraise our situation affectively. We feel good or bad about particular things and our mood level signals overall adaptation. As in animals these affective appraisals are automatic, but unlike other animals humans can reflect on this experience. We have an idea of how we have felt over the last year, while a cat does not. Humans can also judge life cognitively by comparing life as it is with notions of how it should be.

Happiness can be defined as the degree to which a person evaluates the overall quality of his or her present life-as-a-whole positively. In other words, how much the person likes the life he/she leads ${ }^{3}$. This evaluation appears to draw on affective information in the first place, if people appraise how happy there are, they estimate how well they feel most of the time (Veenhoven 1997: section 5). 


\subsubsection{Analogous concepts in biology}

In evolutionary biology, external living conditions are referred to as the 'biotope' or 'habitat'. A biotope can be a more or less suitable for a species, depending on e.g. availability of food, shelter and competition. This is analogous to what I call 'livability'.

An organism's capability to survive in the environment is called 'fitness' by biologists. This latter term acknowledges the fact that the capabilities must meet (fit) environmental demand. This is equivalent to what I call 'life-ability'

With respect to outcomes of life biologists also distinguish between external and internal effects. External effects are various ecological functions, such as being prey for other creatures, and the continuation of the species. This is analogous to what I call the 'utility' of life.

The outcome of life for the organism itself is depicted as 'survival', which is seen to result from the fit between capabilities and environment. This notion corresponds to what I call 'enjoyment of life'. Below I will argue that this is more than mere correspondence, because subjective enjoyment is also a result of fit between individual abilities and environmental demands.

These biological concepts are summarized in Table 2.2.

\subsection{Measuring quality of life}

Quality of life in nations is usually measured using indexes that involve indicators from each of the quadrants in Table 2.1, for instance the Human Development Index (UNDP 1990) includes income per head (top left), education (top right) and life expectancy (bottom right). Yet this makes no sense and the tables help us to see why not.

\subsubsection{Comprehensive measurement not possible}

Quality of life cannot be measured by totaling quadrants. There is no point in combining the qualities in the upper and the lower half of table 2.1, since this involves the adding of chances and outcomes. Combining the qualities at the left and the right makes little sense either and in particular not in the case of life chances, where it is not the sum that matters, but rather the fit between external conditions and inner capacities.

Still another problem is that three of these four qualities cannot be measured very well. We can only make guesses about the features that constitute the livability of an environment and it is also quite difficult to establish what abilities are most required. Though it is clear that some necessities must be met, it is not so clear what is required on top of these, and in what quantities and in what mix. Measuring the utility of life is not really feasible either, since external effects are quite diverse and often difficult to assess. Due to this lack of sound scientific criteria, any measurements depend very much on assumption and ideology and hence there is little agreement how to measure these qualities of life.

Measuring happiness is less problematic however. Since happiness is an overall judgement of life, we cease to have the problem of trying to add and compare apples and oranges: as happiness a state of mind for an individual we can assess it rather easily by asking that person how happy he or she feels. 


\subsubsection{Most inclusive measure is how long and happy people live}

In biology, 'survival' is assumed to result from the 'fit' between the abilities of the organism and environmental demands. This fit cannot be observed as such, but is typically inferred from survival rates. If an organism perishes before its programmed lifetime, there is apparently something wrong with this chance constellation.

In this line, we can also infer the life chances in a human society from the outcomes in happiness. If people live happily, their environment is apparently sufficiently livable and their abilities appropriate. This may not appeal to supporters of the theory that happiness is a culturally constructed illusion ${ }^{4}$, but it fits well with the view that happiness is a biological signal of how well we thrive ${ }^{5}$

In simple animals, good adaptation reflects only in survival, in higher animals, good adaptation also reflects in hedonic experience. Negative affect is indicative of poor adaptation and tends to inhibit the organism, while positive affect is indicative of good adaptation and works as a 'go' signal (Frederickson, Nesse 2004). So, an animal that does not feel good is probably not doing well.

This inner experience is no great issue in biology, because we cannot assess how animals feel. Still there is ground to see hedonic experience as an additional manifestation of good adaptation and in this vein one could argue that an animal that feels well most of its lifetime seems to be better adapted than an animal that lives equally long but feels less well.

Humans are capable of reflecting on their experiences, and can condense positive and negative affects into an overall appraisal of happiness. They are also capable of communicating that appraisal to investigators. Hence in the case of humans we can use the additional sign of good adaptation and assess how long and happy they live.

The degree to which people live long and happy is denoted in the right bottom quadrant in Table 2.1 and is the most inclusive measure of outcomes of life for the individual. It is also indicative for the qualities denoted by the two top quadrants. If people live long and happy, their environment is apparently sufficiently livable and their life-abilities appropriate. So, this measure covers in fact three of the four quadrants and is therefore the most comprehensive measure of quality-of-life available.

Fairy tales often end with the phrase "and they lived long and happily ever after", which is to say that the characters of the story had a good life. The concept of quality of life is then operationalized as a 'long and happy life'. The reasoning above shows that this makes sense. I have underpinned this position in more detail elsewhere and distinguished this measure of 'apparent' quality-of-life from currents counts of 'presumed' blessing (Veenhoven 1996, 2000a, 2005d).

\subsubsection{Also the most relevant in this context}

This chapter is about the question of whether life is getting better in modern society. As such it concerns the outcomes of life and not assumed chances for a good life. What we want to know is how modern chance constellations work out on the final results of life. Likewise, the question is not about the environmental chances, but about the outcomes for individuals. If we do not keep these matters apart, societal development is easily equated with a better life. So this is another reason to focus on the right bottom quadrant, which is best measured by how long and happy people live. 


\subsection{Measure of happy life years}

The degree to which people live long and happy in a society can be measured by combining two sources of information: average longevity in the country and average happiness.

\subsubsection{Measurement of longevity in nations}

How long people live in a country can be assessed using civil registration and by assessing the average number of years between birth and death. This will give an adequate measure for past generations, but not those still alive. Hence, a next step is to estimate how long the living remain alive and these estimates can be generalized to give a general population average. This estimate is called 'life expectancy' and is commonly used in world health statistics. Data is available for almost all countries in the world and yearly updates are published in the Human Development Reports (UNDP 2004).

\subsubsection{Measurement of happiness in nations}

At first sight it is more difficult to assess average happiness in nations, the concept of happiness being reputed as elusive. This may be true for some conceptions of happiness, but not for happiness as defined here. Above happiness was defined as 'the degree to which a person evaluates the overall quality of his or her present life-as-a-whole positively'. In this sense happiness is something that people have on their mind and that they are aware of. Consequently happiness in this sense can be measured by asking people how much they enjoy their life-as-a-whole. Such questions can be posed in various contexts, clinical interviews, life-review questionnaires and common survey interviews. Survey questions can be posed in different ways, directly or indirectly and by using single or multiple items. A common direct single survey question is:

Taking all together, how satisfied or dissatisfied are you currently with your life as a whole?

$\begin{array}{cccccccccc}1 & 2 & 3 & 4 & 5 & 6 & 7 & 8 & 9 & 10 \\ \text { Dissatisfied } & & & & & & & & & \text { Satisfied }\end{array}$

There are many qualms about such simple self-reports of happiness, in particular about their validity and about comparability accross nations. Elsewhere I have considered the objections and inspected the empirical evidence for claims about bias (Veenhoven, 1993, 1997). I found no proof for any of the objections, so I assume that happiness can be measured in this way. Others have come to the same conclusion (Diener 1994, Saris 1998). Suffice to note that cross-national differences in happiness correspond in the predicted way with national rates of depression (VanHemert 2002), and suicide ( $\mathrm{r}=-.46$; own analysis).

It is now generally agreed that happiness can be measured in this way and a large literature on empirical happiness research ${ }^{6}$ has developed since the 1970. Reviews of that literature can be found with Myers (1992), Diener et. al. (1999) and Veenhoven (2006a). This research tradition has resulted in a growing body of data on happiness in nations. Presently there are comparable surveys in 91 nations. These data have been brought together in the 'World Database of Happiness' (Veenhoven 2006b) and will be used here. 


\subsubsection{Combination with longevity}

How long and happy people live in a country can be measured by combining information about length of life, drawn from civil registrations of births and deaths, with data on average appreciation of life as assessed in surveys. The following simple formula can be applied:

\section{Happy-Life-Years = Life-expectancy at birth $x$ 0-1 happiness}

Suppose that life expectancy in a country is 60 years, and that the average score on a 0 to 10 -step happiness scale is 5 . Converted to a $0-1$ scale, the happiness score is than 0,5 . The product of 60 and 0,5 is 30 . So the number of happy life years is 30 in that country. If life expectancy is also 60 years but average happiness 8 , the number of happy life years is 48 $(60 \times 0,8)$.

Theoretically, this indicator has a broad variation. The number of Happy Life Years is zero if nobody can live in the country, and will be endless if society is ideal and/or its inhabitants immortal. The practical range is between about 10 and 70 years. Presently at least, life expectancy at birth in nations varies between 40 and 80 years, while average happiness varies between 0,3 and 0,8. The number of Happy-Life-Years (HLY) will always be lower than standard life expectancy. It can equal real length of life only if everybody is perfectly happy in a country (score 1 on scale 0 to 1 ).

A high HLY means that citizens live both long and happily; a low HLY implies that the life of the average citizen is short and miserable. Medium HLY values can mean three things: 1) both moderate length-of-life and moderate appreciation-of-life, 2) long but unhappy life, and 3) short but happy life. I treat these intermediate outcomes as equal, but one can of course prefer one to the other. I have described this indicator in more detail elsewhere (Veenhoven 1996, 2000a, 2005d). It scored highest in a scholarly review of social indicators (Hagerty et. al. 2001). In a similar way the World Health Organization measures 'Disability Adjusted Life Years' (DALYs) in nations (WHO 2004). In this case, life expectancy is weighted with a disability score, which is typically also derived from survey data. Because disabilities increase with age, age composition in nations must be taken into account in crossnational comparisons of DALY's. In the case of HLY this is not required, because happiness is not related to age in the same way. There is a slight U-shaped pattern in the relation between happiness and age, happiness tending to be somewhat lower around middle age, yet this effect is not so robust that it requires correction.

\section{QUALITY OF LIFE IN MODERN SOCIETY}

Using this indicator, we can now answer the question whether life is getting better or worse in modern society. For this purpose I will first compare the quality-of-life in developed and under-developed countries at the present time and next consider the available data on trends over the last decades. 
3.1 Difference in Happy Life Years between more and less modern nations in the 1990s The present day world counts about 150 nations and for $90^{7}$ of these we know how long and how happy its citizens lived in the 1990s. See the list on the World Database of Happiness (Veenhoven 2005a). These cases represent more than half of the nations in the present day world and cover about two-thirds of the world's population, since all the big countries are included.

The level of modernity or 'development' of these nations can be measured in different ways; since there are different views on the essence of modernity, there are also different indicators of the matter. Some focus on the mode of production and measure modernity by the ratio of agrarian and industrial production, whereas others see mental development as the core and measure modernity using the average level of education. There are also several multi-dimensional indicators of modernity, such as the Human Development Index mentioned above and the Index of Social Progress (Estes 1984). All these measures appear to be highly correlated with buying power per head (UNPD 2000), and since this measure is available for all the nations I use it in this analysis. In the scattergram of Figure 2.1, the number of happy life years is plotted vertically and income per head horizontally. One can easily see that there is a strong correlation, HLY being systematically higher in rich nations than in poor ones. The correlation is +.77.

The use of other indicators of modernity yields similar results. HLY is also positively correlated with industrialization $(r=+.43)$, informatisation $(r=+.70)$, urbanization $(\mathrm{r}=+.55)$, and also with individualization $(\mathrm{r}=+.66)$. The correlations are strong and leave no doubt that people live longer and happier in the most modern societies. This point is elaborated in more detail elsewhere (Bernheim \& Heylighen 2000, Diener \& Diener 1996).

The pattern is similar if we consider happiness and longevity separately. The correlation of modernity, as measured by income per head, with average happiness is +.72 and the correlation with life-expectancy +.65 . These effects are largely independent; controlling for life expectancy, the partial correlation of modernity with happiness is still +.64 and controlling for happiness, the partial correlation of modernity with lifeexpectancy is +.75 ! This independence of the effects is another justification for the use of this combined measure of happy life years.

\subsection{Trend of Happy Life Years in modern nations over the last decades}

The differences observed in the cross-sectional analysis above could be due to intervening variables, for example they may be due to the fact that modern nations are mainly found in moderate climate zones or to variation in genetic endowment. Such distortions can be controlled for if we compare over time within separate nations. If life is getting better, this must also manifest in a positive trend.

Assessment of the development in HLYs in nations requires trend data on happiness and life expectancy. In the case of life expectancy this is no problem, since considerable time series are available for many nations. Time series on happiness are less abundant however. Series of thirty years or longer and based on identical survey questions are available for only 10 nations and these are all highly developed ones.

Eight of these nations are the early EU members, which have participated in the Eurobarometer survey since 1973. These nations are Denmark, Belgium, France, West Germany, Italy, Luxembourg, The Netherlands and the UK. Figure 2.2 presents the trend 
in HLYs in these countries from 1973 to 1999. A clear positive trend emerges, HLY rose from 46,5 in 1973 to 51,3 in 1999. The linear regression coefficient is +.204 and this trend is significantly different from zero, since the $95 \%$ confidence interval ranges between +.167 and +.241 . If this trend continues, West-Europeans will live 62,2 happy years in $2050^{8}$, which would mean a gain of 15,7 years in less than a century. Similar trends are observed in the other developed nations for which data are available. On Table 2.3 we can see that this rise in HLY has also occurred in the USA and in Japan.

In most cases this pattern is due to a simultaneous rise in happiness and longevity. Yet in the UK and the USA subjective appreciation of life has remained the same and the rise in HLY is due to the lengthening of life. There is only one case of a slight decline in happiness, and that is Japan. This case is analyzed elsewhere (Stam \& Veenhoven 2005).

The right column in Table 2.3 presents the estimated rise in HLY from 1973 to 2002 in all these countries. The gains are substantial, in Luxemburg more then 7 HLYs! The increases are less spectacular in most other countries, but still considerable, for instance 4,2 years in the USA.

The data do not suggest that there is a catch-up effect of greater gains in countries where HLY was low in 1973. The highest gains are observed in Luxemburg and Denmark, which scored high at the start, while the lowest gain is observed in Japan, which started at the bottom. Still, France and Italy are cases of a low start, with a big gain.

This upward trend is not the result of the happy getting happier, but rather the result of a reduction in the number of very unhappy persons in the population. This manifests in a lowering of the standard deviations in all nations, also in the ones where the average remained at the same level (Veenhoven 2005c). Likewise, the gains in life expectancy are greater at the bottom of the distribution than at the top. So the rise in HLY went together with a reduction of inequality in quality of life.

All this shows that life is getting better rather than worse, at least in the most modern nations of today.

\subsection{Temporary drops}

This is not to say that life has got better in all countries during the last decades, HLY has not risen in Belgium, due to a decline in happiness in the 1980s. Happiness and longevity dramatically plunged in the former communist countries in the 1990s, in particular in Russia (Veenhoven 2001), probably in response to the sudden transformations in these societies. The latest data suggest that the post-communist nadir is passed.

One must also realize that the effects of economic development are less smooth than suggested in Figure 2.1. In some cases at least, early industrialization was accompanied by a shortening of life and even by a reduction in average body size (Komlos 1998). The wide variation in the left half of Figure 2.1 can be interpreted as an indication that similar things are happening in today's developing nations. Further it is beyond doubt that progress causes the 'pain of incomprehension' during periods of transition (Hays, 1994). 


\section{QUALITY-OF-LIFE OVER HUMAN HISTORY}

The above evidence concerns contemporary societies and does not rule out that qualityof-life has been better in earlier times. All the countries considered are modern to some extent. Hence these data cannot settle the question of whether we would have lived better in an ancient society.

One way to check this would be to look at the quality-of-life in present day 'primitive' societies. Yet there are few such societies today and the few that remain live typically live in poor ecological conditions, impinged on by 'modern' society to their detriment, i.e. being brought into contact with diseases to which they have little or no resistance and their habitat being destroyed by logging and mining. Moreover, the last century's anthropological research does not give us a clear picture of the quality-of-life in the primitive societies that were surveyed. There are accounts of positive features in such societies, such as Mead's (1953) description of relaxed sexual practices in Samoa, but there is also evidence of rampant evils, such as violence and superstition (Edgerton 1992). Anthropologists have never attempted to assess happiness, possibly because of their belief in cultural relativism.

Still, important clues can be found in historical anthropology and in particular in work by Maryanski and Turner (1992) and Sanderson (1995). This literature departs from the insight that the human species developed in the context of hunter-gatherer bands and that this type of social organization prevailed for most of the 100.000 years that Homo sapiens has existed. More complex kinds of societies seem to have developed only fairly recently in human history, first horticultural societies, then agrarian societies and finally our present day industrial society, which is rapidly becoming post-industrial in the west (Lenski et. al. 1995, chapter 1). There are good indications that these types of societies were not equally livable, and in particular that the agrarian phase marked a historic dip in human quality-of-life.

\subsection{Less free in agrarian society}

One indication is that the development of freedom seems to have followed a U-curve over human history. Hunter-gatherer societies can impose few constraints on their members, since dissenters can support themselves for a while and join other bands. Accumulation of wealth and power is difficult, if not impossible, in these conditions and hence this kind of society tends to be free and egalitarian.

This changed profoundly in an agrarian society, where survival requires control of the land and people became more dependent on their family and vulnerable to exploitation by a warrior caste. According to Maryanski and Turner (1992) this drove mankind into the 'social cage' of collectivistic society. In their view, such strong social bonds are less required in the context of industrial existence, not only because individuals get access to more relational alternatives, but also because the ongoing division of labor involves a shift of dependencies to anonymous institutions such as the state. Durkheim (1897) described that latter phenomenon as the change from 'mechanic solidarity' to 'organic solidarity'.

This theory fits the above observation that people live happier in the most modern societies of this time and in particular it fits the observed relation between happiness and 
freedom in nations (Veenhoven 1999). It also provides an explanation for the ongoing migration from the land to cities.

\subsection{Less healthy in agrarian society}

Another sign of the low quality-of-life in agrarian society can be found in anthropometric indicators of health. The average health of past generations can to some extend be reconstructed from human remains. On the basis of excavated bones and teeth we can estimate how long people have lived and to some degree how healthy they were when they lived.

Research along these lines suggests that people lived about equally long in early hunter-gatherer societies and later agrarian societies, but that they lived more healthily in the former than in the latter. Hunter-gatherers appear to have been better-nourished and less disease ridden than historical agrarian populations and they seem to have been less burdened with work. Much of the literature on this subject is reviewed in Sanderson (1995: 340-3). Apparently, the obvious advantages of a sedentary pastoral life are counter balanced in some way, amongst other things probably by increased exposure to disease and to social stress.

Present day industrial societies score better on anthropometric indicators than both of the other types do. We live longer and healthier than ever and also grow taller than our forefathers ever did.

Such historical data cover health and longevity and can be combined in an index of healthy life years that concurs with the measure of 'Disability Adjusted Life Years' that is currently used by the World Health Organization (WHO 2004). This resembles the 'Happy Life Years' I used in the above analysis of contemporary nations, but it is not quite the same. Since survey research is a recent invention we will probably never know how happy people were in the past. Hence we must make do with the available data on health and longevity. Still, these matters appear to be strongly correlated with happiness ${ }^{9}$ and both can be seen as manifestations of human thriving.

If we consider the data on longevity it is also easy to see that our forefathers cannot have lived as many happy years as we do now. The average length of life was about 45, both in a hunter-gatherer society and in an agrarian society. This means that the HLY could not be higher than 45, even if everybody was perfectly happy. This is clearly below the level in present day modern nations, where HLY varies between 50 and 60 (cf. Figure 2.1).

\subsection{Long term pattern}

Together these data suggest that societal evolution has worked out differently on the quality of human life, first negatively in the change from hunter-gatherer existence to agriculture and next positively in the recent transformation from an agrarian to an industrial society. This pattern is depicted graphically in Figure 2.3.

It is not unlikely that the upward trend will continue in the future, both happiness and longevity are likely to rise.

Currently average happiness ranges between 3,2 (Tanzania) and 8 (Switzerland). This means that there is still much to win. There is no reason to assume that Tanzania can never reach the level of Switzerland. Possibly, average happiness can even go above an average of 8 . The maximally possible average may be close to 9 . An average of 10 in a 
nation is clearly not possible, not only because human life involves inevitable suffering but also because no society can serve everybody's needs equally well.

It is also quite likely that longevity will continue to rise. The underdeveloped nations are catching up at an unprecedented rate, and there is reason to expect that longevity will further extend in the developed world, among other things as the result of medical technology. There is speculation that the average life might be extended to 100 years or more (Manton 1991, Vaupel \& Lundström 1993). As yet, gains in length of life have not come at the cost of quality of life. Elderly people appear to be slightly happier than the middle-aged Okma \&Veenhoven (1999).

The dotted trend line at the right side of Figure 2.3 depicts these projections.

\section{DISCUSSION}

These findings raise several questions: one is about compatibility with claims to the contrary, and in particular with reports of alarming rises in rates of depression in modern society. A second question is what are the mechanisms behind the recent rise in the quality of human life and the third is to ask why progress pessimism still prevails in the social sciences.

\subsection{No 'loss of happiness in market democracies'?}

The results of this study directly contradict those of Robert Lane (2000). In his muchcited book "The loss of happiness in advanced market democracies", Lane presents evidence of declining happiness using similar survey data. How does he come to such a different conclusion? The first answer is that Lane considers only the case of the USA. As shown in Table 2.3, happiness rose only slightly in this country. Secondly, Lane presents data for an era when happiness declined slightly in the USA, i.e. the years 19721994. When we consider the period 1973-2002, we see no decline but rather an increase and when we consider all the available data from 1949 on we also see no decline. Thirdly, Lane only considers the trend for 'very happy' responses and thus fails to acknowledge that the percentage of 'unhappy' responses has declined. Ott (2001) has discussed these flaws in more detail. Fourthly, Lane has considered the responses to the happiness question in the General Social Surveys that show little variation over time ${ }^{10}$. Yet there is a positive trend in the responses on two other questions used in periodical Gallup polls (Veenhoven 2005b). Lastly, Lane does not acknowledge that Americans live longer now and that this is a blessing given their high level of happiness. In his eagerness to promote 'the medicine of more companionship', Lane has overstated the disease.

\subsection{No contradiction with rising rates of depression?}

Mental illness is no exception in modern societies, about $16 \%$ of the US citizens have experienced episodes of serious depression and every year depression interferes with effective functioning of some $6 \%$ of them for two weeks or more. There are signs of increasing rates of depression, especially among youth and there is talk about a depression epidemic (Seligman 1990: 10). How does this fit with a rising number of happy life years?

The first thing to note is that depression is strongly correlated with happiness. Depressed individuals are clearly less happy and there is a strong correlation between 
rates of depression and average happiness in nations (VanHemert 2002). A second point to keep in mind is that depression is temporary in most cases, and good times can balance the bad times. Thirdly, we are not sure that the rate of depression has risen. There is an increase in the numbers for people diagnosed as being depressed, but this may due to better recognition by professionals of the signs of depression and by better treatments being available to treat depression. It is possible that depression is less well recognized in under developed nations, not only because the people are less aware of the syndrome, but also because bad feelings can be more easily attributed to bad conditions. However it is also possible that in modern societies people are more aware of how they feel, because they have more choice and use how they feel more to help them to assess what they want.

If there is a real rise in rates of depression in modern society, that can still co-exist with a rise in average happiness. Modernization can be to the advantage of a majority, but can come at the expense of a minority, who are pushed into depression; no society can suit the needs of all equally well. If this has happened at all, it has not resulted in a split between happy and unhappy, since the dispersion of happiness is lessening in modern societies (Veenhoven 2005c).

\subsection{Why is life getting better?}

The observed growth of years lived happily and healthily can be attributed to several factors. One is obviously that several common evils of the past have been overcome in modern societies or at least much abated. For instance, few in the West die of hunger anymore and the chance of being killed is greatly reduced. A second factor is in the increased freedom in modern individualized society. The social system allows us more opportunity to choose and we have also become more capable of making choices which, taken together, has increased our chance that we will live a life that fits our individual needs (Veenhoven 1999). This links up with a third explanation, which is that modern society provides a challenging environment that fits an innate human need for selfactualization. In this view, the human species evolved in rather tough conditions and therefore typically thrives in modern society with its complexities, competition and choices $^{11}$. Probably, increased self-understanding has also contributed to the quality-oflife of modern man. Lastly, a more 'critical' explanation could be that the modern nations successfully exploit the rest of the world. There may be some truth in this contention, but life is also getting better in most non-western nations. Most of the poor countries became less poor over the last decade and life expectancy is also rising in most countries (UNDP , 2004).

\subsection{Why then do we still believe that life is getting worse?}

This leaves us with the question of why so many people think that our quality of life is decreasing and, in particular, why this belief is so strong among trained society watchers. One answer to this question is that we tend to overestimate present problems; yesterday's problems are not only less vivid in our minds, but we also know that we survived them. This may link up with an innate tendency to be alert to signs of danger. This perceptual bias is enhanced by the professional interest of journalists and social scientists who earn their living dealing with social problems and for that reason tend to emphasize evil. These tendencies seem to veil our awareness of actual improvements in the quality of the 
life we live. Possibly this works as a self-denying prophecy; the overstatement of problems results in timely solutions.

\section{CONCLUSION}

Societal evolution has not always improved the quality of life. The change from huntergatherer bands to agrarian society seems to have involved deterioration, but the later transition to modern industrial society brought a change for the better. We now live longer and are healthier than ever before and we are probably also happier. There are good reasons to believe that this trend will continue in the near future. 
Figure 2.1

Happy Life Years and income per head in 90 nations in the 1990s

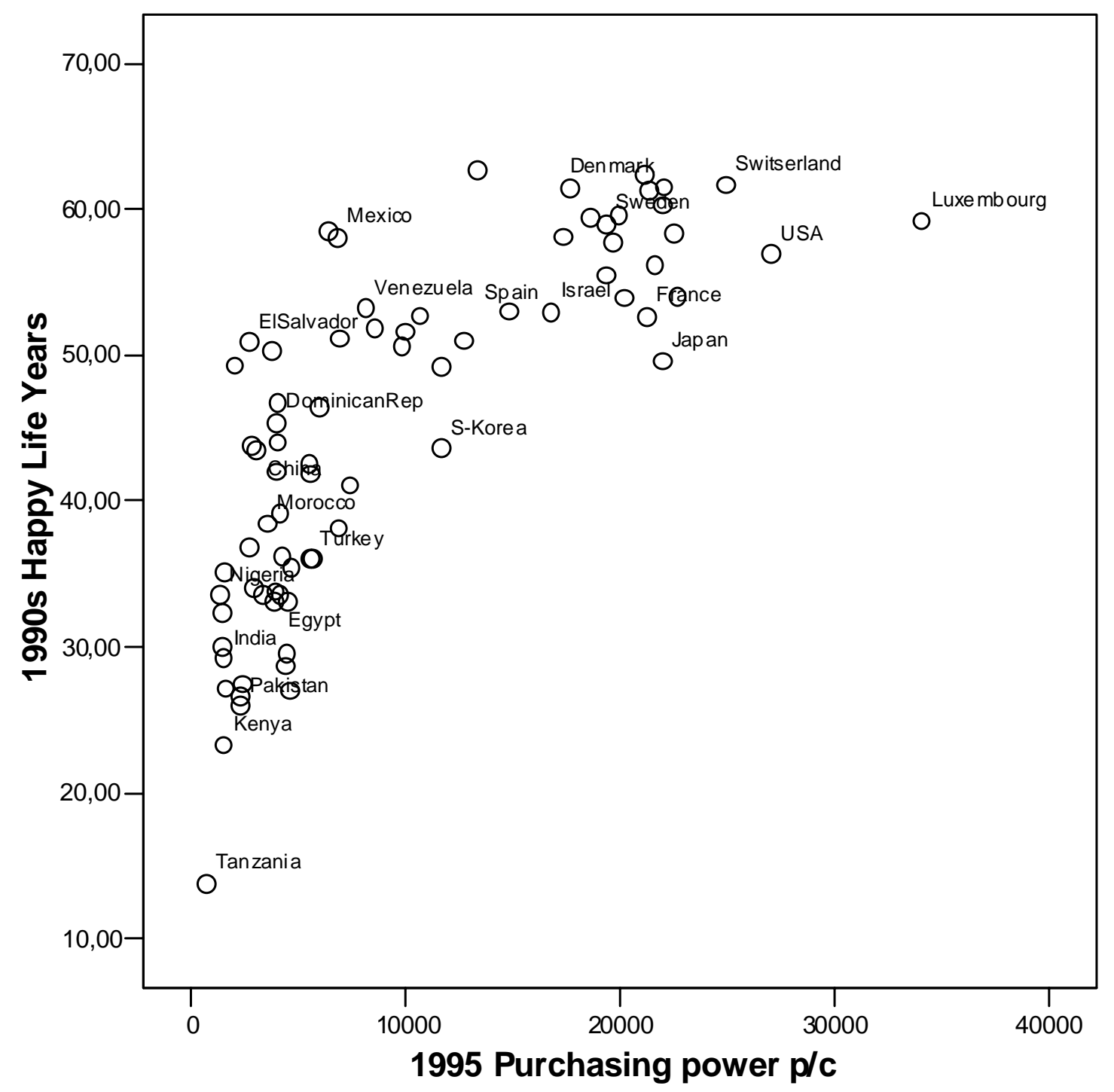


Figure 2.2

Trend Happy Life Years in 8 EU-nations 1973-2002

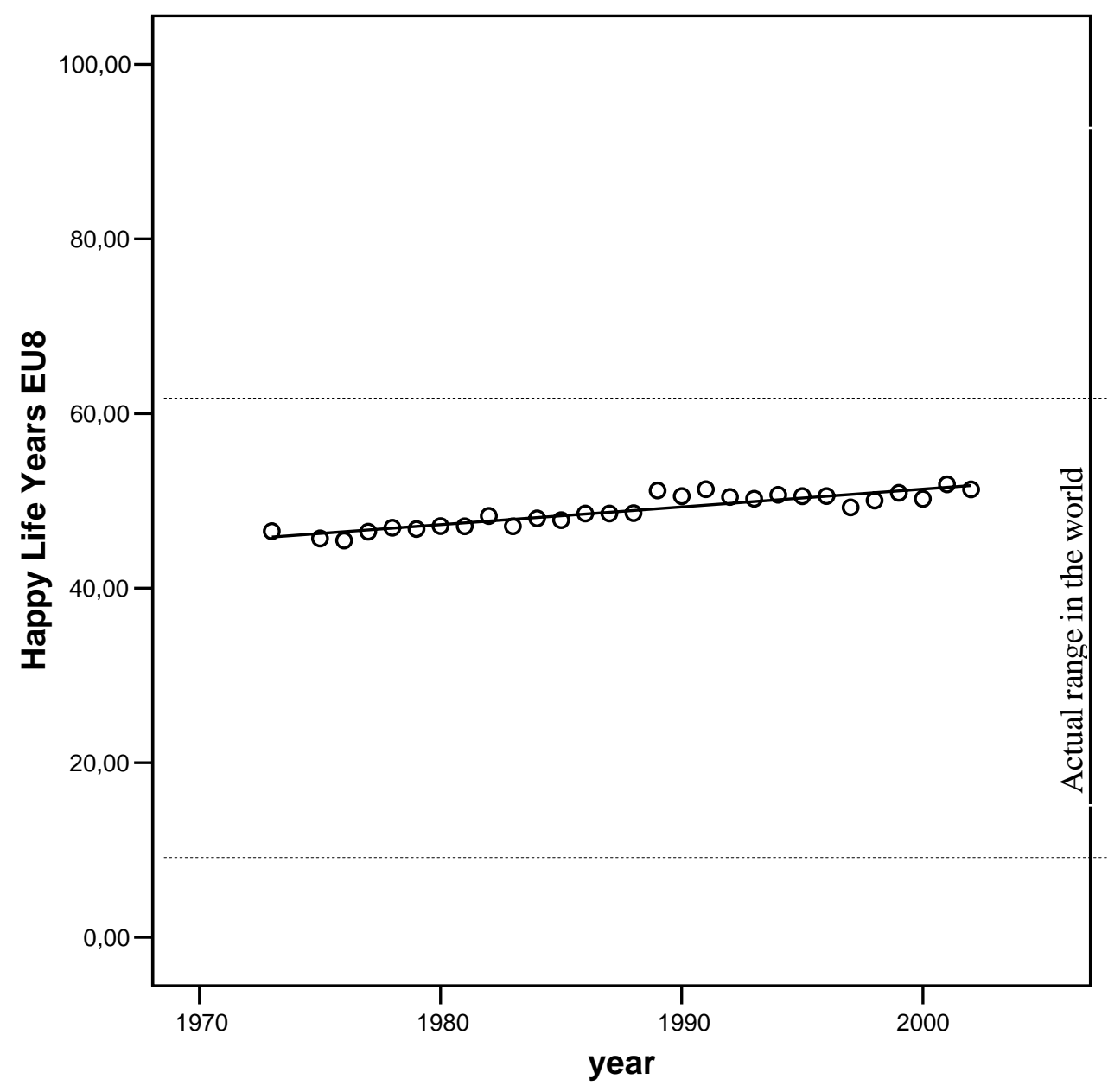


Figure 2.3

\section{Long-term trend in quality of life}

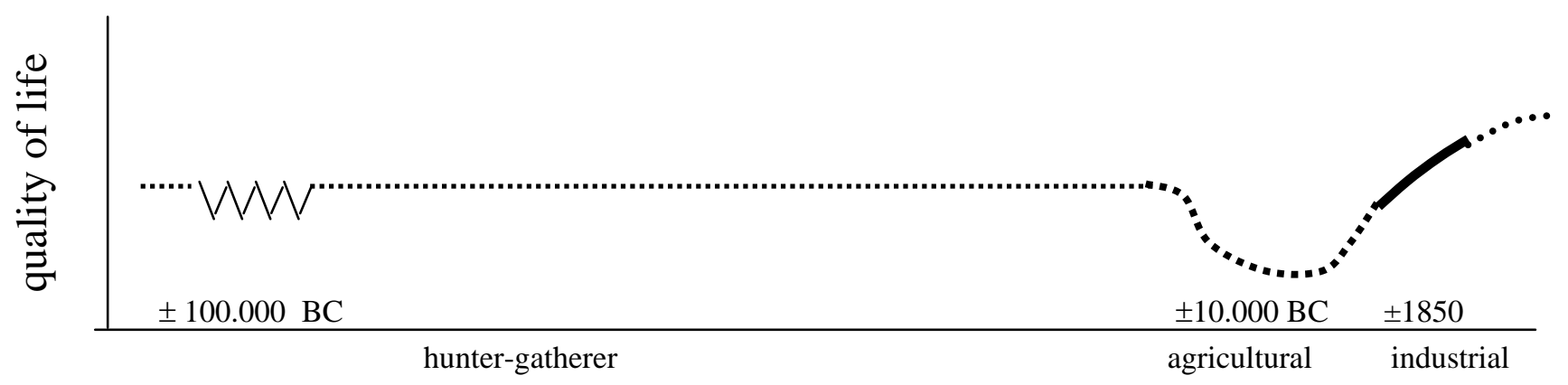


Table 2.1

Four qualities of life

\begin{tabular}{|l|c|c|}
\hline & Outer qualities & Inner qualities \\
\hline Life chances & Livability of environment & Life-ability of the person \\
\hline Life results & Utility of life & Enjoyment of life \\
\hline
\end{tabular}

Table 2.2

Comparable concepts in biology

\begin{tabular}{|l|r|c|}
\hline & Outer quality & Inner quality \\
\hline Life chances & Biotope & Fitness \\
\hline Life results & Continuation of species & Survival \\
& Ecological functions & \\
\hline
\end{tabular}


Table 2.3

Trend in Happy-Life-Years in some modern nations 1973-2002

\begin{tabular}{|c|c|c|c|c|}
\hline \multirow[t]{2}{*}{ Nation } & \multicolumn{3}{|c|}{$\begin{array}{c}\text { Trend } \\
\text { (Expressed in linear regression coefficient) }\end{array}$} & \multirow{2}{*}{$\begin{array}{c}\text { Rise } \\
\text { of } \\
\text { Happy } \\
\text { Years }\end{array}$} \\
\hline & Happiness & Life expectancy & Happy Life Years & \\
\hline Italy & +.03 & +.25 & +.40 & $+11,5$ \\
\hline Luxemburg & +.01 & +.26 & +.26 & $+7,6$ \\
\hline Denmark & +.02 & +.12 & +.21 & +6.0 \\
\hline France & +.01 & +.25 & +.21 & +6.0 \\
\hline USA & +.01 & +.17 & $+.18^{12}$ & +5.2 \\
\hline Germany (W) & -.00 & +.22 & +.15 & +4.4 \\
\hline UK & +.00 & +.18 & +.14 & +4.1 \\
\hline Netherlands & +.00 & +.15 & +.13 & +3.8 \\
\hline Japan & -.00 & +.27 & $+.15^{13}$ & +4.4 \\
\hline Belgium & -.02 & +.23 & -.04 & -1.0 \\
\hline
\end{tabular}

All regression coefficients within 95\% confidence interval, except one in italics Source: Veenhoven 2005a 


\section{REFERENCES}

Braverman, H. (1974)

Labor and monopoly capital: The degradation of work in the $20^{\text {th }}$ century

Monthly Review press, New York, USA

Danner, D.D., Snowdow, D.A. \& Friesen, W.V. (2001)

Positive emotions in early life and longevity Findings from the nun study

Journal of Personality and Social Psychology, vol.80, pp. 804 - 813

Deeg, D.J. \& Van Zonneveld, R.J. (1989)

Does happiness lengthen life? The prediction of longevity in the elderly

Veenhoven, R. (Ed.): 'How harmful is happiness? Consequences of enjoying life or not'

Universitaire Pers Rotterdam, Netherlands, pp. 29 - 34

Diener, E. (1994)

Assessing subjective wellbeing: progress and opportunities

Social Indicators Research, 1994, Vol. 31, 103 - 157

Diener, E. \& Diener C. (1996)

Most people are happy

Psychological Science, 1996, Vol. 7, 181 -185

Diener, E., Lucas, R.E., Smith, H.L. \& Suh, E.M. (1999)

Subjective well-being: three decades of progress

Psychological Bulletin, 1999, Vol. 125, 276 - 301

Durkheim, E. (1897)

Le suicide : étude de sociologie

Alcan, Paris, France

Easterbrook, G. (2003)

The progress paradox: How life gets better while people feel worse

Random House, New York, USA

Edgerton, R.B. (1992)

Sick societies; challenging the myth of primitive harmony

The Free Press, New York, USA

Elchardus, M. (2004)

Sociologie in de onbehaaglijke samenleving (Sociology in uncomfortable society)

Sociologische Gids, Vol. 51, 507 - 515 
Estes, R.J. (1984)

The social progress of nations

Praeger, New York, USA

Freud, S (1930)

Das Unbehagen in der Kultur

Abriss der Psychoanalyse; Fisher, Frankfurt am Main, Germany

Translated as “Civilization and its discontents' Norton, 1961, New York

Hagerty, M.R., Cummins, R.A., Ferris, A.L., Land, K., Michalos, A.C., Peterson, M., Sirgy, J. Sharp, A. \& Vogel, J. (2001)

Quality of Life Indexes for National Policy: Review and Agenda for Research

Social Indicators Research, Vol. 5, 1 - 96

Hagerty, M.R. (2003)

Was life better in the 'good old days'? Inter temporal judgement of life-satisfaction Journal of Happiness Studies, Vol. 4, 115 - 139

Hays, D.G. (1994)

On the painfulness of progress

Cross-Cultural Research, Vol. 28, 322 - 326

Heylighen, F. \& Bernheim, J. (2000)

Global progress I; Empirical evidence for ongoing increase in quality of life

Journal of Happiness Studies, Vol. 1, 293-321

Komlos, J. (1998)

Shrinking in a growing economy? The mystery of physical stature during the industrial revolution

The Journal of Economic History, Vol. 58, 779 - 802

Lane, R. (2000)

The loss of happiness in market democracies

Yale University Press, New Haven, NJ, USA

Lenski, G., Nolan, P. \& Lenski, J. (1995)

Human societies; an introduction into macro sociology

McGraw-Hill, New York, USA

Manton, K.E., Stallard, H.D.\& Tolley, (1991)

Limits to human life expectancy: Evidence prospects, and implications

Population and Development Review, vol.17, pp. 603-637. 
Maryanski, A. \& Turner, J.H. (1992)

The social cage, human nature and the evolution of society

Stanford University Press, California, USA

Marx, K (1871)

Das Kapital

Collected works, Akademie Verlag, Berlin Germany

Translated as 'Capital: a critique of political economy' Lawrence \& Wishart, London, UK

Mead, M. (1953)

Coming to age in Samoa: a psychological study of primitive youth for Western

civilization

Modern Library, New York, USA

Moore, S. \& Simon, J.L. (2000)

It's getting better all the time. Greatest trends of the last 100 years

Cato Institute, Washington, USA

Myers, D. G. (1992)

The pursuit of happiness. Who is happy and why?

William Morrow, New York, USA

Nesse, R.M. (2004)

Natural selection and the elusiveness of happiness

Philosophical Transactions of the Royal Society, Biological Sciences, Vol. 359, 1333 1347

Okma, P. \& Veenhoven, R. (1999)

Is langer leven nog wel leuk (Happiness of the very old in $8 \mathrm{EU}$ nations)

Sociale Wetenschappen, vol. 42, pp. 38-62

Ott, J.C. (2001)

Did the market depress happiness in the US?

Journal of Happiness Studies, Vol. 2, 433 - 443

Putnam, R.D. (2000)

Bowling alone: the collapse and revival of American community

Simon \& Schuster, New York, USA

Riesman, D. (1950)

Lonely crowd: a study of the changing American character

Yale University Press, New Haven, USA 
Ritzer, G. (1993)

The McDonaldization of society

Pine Forge Press, Thousand Oaks, CA, USA

Sanderson, S.K. (1995)

Social transformations

Blackwell, UK

Saris, W., Scherpenzeel, A.C. \& VanWijk, T. (1998)

Validity and Reliability of Subjective Social Indicators

Social Indicators Research, 1998, Vol. 45, 173 - 199

Seligman, M.E. (1990)

Learned optimism

New York Pocket Books, USA

Stam, J. \& Veenhoven R. (Eds) (2007)

Quality of life in Japan and The Netherlands

Brill, Leiden, The Netherlands

UNPD (1990, 2000, 2004)

Human development report

United Nations Development Program (UNDP)

Oxford University Press, New York, USA

VanHemert, D.A., VandeVijver, F. \& Poortinga, Y.P. (2002)

The Beck depression inventory as a measure of subjective wellbeing in a cross-national study

Journal of Happiness Studies, Vol. 3, 257 - 286

Vaupel, J.W., H. Lundström, (1993)

The future of mortality at older ages in developed countries.

W. Lutz (Ed.): The future population of the world: What can we assume today?

IIASA. Earthscan Publications, Ltd. London, UK

Veenhoven, R. (1984)

Conditions of happiness

Kluwer Academic, Dordrecht, Netherlands

Veenhoven, R. (1991)

Is happiness relative?

Social Indicators Research, Vol. 24, 1 - 34 
Veenhoven, R. (1995)

The cross-cultural pattern of happiness. Test of predictions implied in three theories of happiness

Social Indicators Research, Vol. 34, 33 - 68

Veenhoven, R. (1993)

Happiness in nations

RISBO, Rotterdam, The Netherlands. A 2004 update is available on:

www2.eur.nl/fsw/research/happiness

Veenhoven, R. (1996)

Happy life-expectancy: A comprehensive measure of quality-of-life in nations

Social Indicators Research, Vol. 39, 1 - 58

Veenhoven, R. (1997)

Progrès dans la compréhension du bonheur

Revue Québécoise de Psychologie, Vol 18, 29 - 74

English version available on: www2.eur.nl/fsw/research/veenhoven

Veenhoven, R. (1999)

Quality-of-life in individualistic society: A comparison of 43 nations in the early 1990s

Social Indicators Research, Vol. 48, 157 - 186

Veenhoven, R. (2000a)

The four qualities of life: Ordering concepts and measures of the good life

Journal of Happiness Studies, Vol. 1, 1 - 39

Veenhoven, R. (2000b)

Wellbeing in the welfare state, level not higher distribution not more equitable

Journal of Comparative Policy Analysis, Vol. 2, 91 - 125

Veenhoven, R. (2001)

Are the Russians as unhappy as they say they are?

Journal of Happiness Studies, Vol. 2, 111 - 136

Veenhoven, R. (2005a)

Happy Life Years in 90 nations 1990-2000; How long and happy people live

World Database of Happiness, Distributional findings in nations, Rank Report 2005/2c

Available at: www2.eur.nl/fsw/research/happiness

Veenhoven, R. (2005b)

Trend Happy Life Years in Nations, 1946-2002

World Database of Happiness, Happiness in nations, Trend Report 2005-2c

Available at: www2.eur.nl/fsw/research/happiness 
Veenhoven, R (2005c)

Return of inequality in modern society? Test by dispersion of life-satisfaction across time and nations

Journal of Happiness Studies, Special issue on 'Inequality of happiness in nations', in press

Veenhoven, R. (2005d)

Apparent quality of life: How long and happy people live

Social Indicators Research, vol. 71, pp. 61-86

Veenhoven, R. (2006a)

Quality-of-life research

in: Bryant, C.D. \& Peck, D.L. (Eds.) 'Handbook of the 21th Century Sociology'

Sage, Thousand Oaks, California, USA In press

Veenhoven (2006b)

World Database of Happiness. Continuous register of scientific research on subjective appreciation of life

Erasmus University Rotterdam, The Netherlands

http://worlddatabaseofhappiness.eur.nl

WHO (2004)

World Health Report 2004

Geneva, Switzerland 


\section{NOTES}

${ }^{1}$ An earlier version of this chapter was presented at the $2^{\text {nd }}$ European conference on Positive Psychology, Pallanza, Italy, July 2004 and published in the European Psychologist, vol. 10 pp. 330-343.

2 The quality of individual life in society is only one of the themes in a wider debate about the quality of society and in fact a rather recent theme. Most of the discourse about societal development is about power, contribution to human civilization and moral value.

${ }^{3}$ I have elaborated this definition in more detail elsewhere (Veenhoven, 1984, chapter 2)

${ }^{4}$ Elsewhere I have discussed this theory and shown that it is wrong (Veenhoven, 1991, 1995)

${ }^{5}$ This signal theory of happiness fits well with the findings of long-term follow-up studies that happiness predicts longevity (Danner 2001) even when initial physical health status is controlled (Deeg \& VanZonneveld 1989)

${ }^{6}$ This research line is also known research by different names, such as: 'Subjective Well-Being' (SWB). 'Life Satisfaction' and 'Positive Affectivity'.

${ }^{7}$ Data on happiness were drawn from the World Value Survey in 80 cases, and from the Penn World Survey in 10 cases. Since difference in questions and framing might influence the results, I also analyzed the 80 WVS countries separately. The result did not change.

${ }^{8}$ This is an illustrative linear extrapolation, which does not take into account that there is a maximum to average happiness and that the trend will probably fall off when approaching this ceiling.

${ }^{9}$ See note 5

${ }^{10}$ The change coefficient of happiness in the USA in Table 2.3 is based on this GSS item, and present the most conservative estimate.

${ }^{11}$ In this line I have explained why people do not thrive better in welfare states (Veenhoven 2000b)

${ }^{12}$ Over the period 1963-2002 the trend in HLY is slightly more positive in the USA: $+.190[+.180 ;+.201]$, which means a gain of 7,41 happy life years.

${ }^{13}$ Over the period 1958-2002 the trend in HLY is clearly positive in Japan: +.147 [+.106;+.188] 